\title{
The Practice of Supporting International Students Learning English in Canada: Grounding Decisions in Evidence and Lived Experience
}

\author{
Alanna Carter, Seneca College
}

\section{Abstract}

This paper is a response to the language, learning, and life needs of the increasing number of international students studying in Canada. In addition to introducing two "real-life" international students who chose to live in Canada to learn English and otherwise study, the paper presents what the literature tells us about: international students in general; culture shock and acculturation; the struggle of international students for identity, based on the International Student Identity model; and mental health issues among this learner group. It then juxtaposes key themes found in the literature with the life experiences of the aforementioned students. Implications for students, extracurricular and

\section{Résumé}

Cet article se veut une réponse à la langue étrangère, à l'apprentissage et aux besoins fondamentaux d'un nombre croissant d'étudiants étrangers venus étudier au Canada. Outre la présentation de deux « vrais » étudiants étrangers qui ont choisi de vivre au Canada pour apprendre l'anglais et étudier, l'article démontre aussi ce que rapporte la littérature scientifique : les étudiants étrangers en général; le choc des cultures et l'acculturation; la lutte des étudiants étrangers pour leur identité, basée sur le modèle d'identité internationale des étudiants; et les questions de santé mentale au sein de ce groupe d'apprenants. II juxtapose ensuite les principaux thèmes de la documentation aux 
preparatory program planners, and classroom instructors are shared. Given the role of many continuing education centres in providing ESL instruction and supports, the paper holds particular value for educators and administrators in the continuing education sector. expériences de vie des étudiants mentionnés ci-dessus. On y partage les implications pour les étudiants, pour les planificateurs de programmes parascolaires et préparatoires, et pour les instructeurs en classe. Étant donné le rôle que tiennent de nombreux centres de formation continue pour fournir du soutien et des directives en matière d'enseignement de l'anglais langue seconde, l'article représente une valeur particulière pour les éducateurs et les administrateurs du secteur de la formation continue.

\section{Introduction}

Countries such as Canada, the United States, the United Kingdom, and Australia compete to attract thousands of international students to study in their colleges, universities, and other educational institutions every year. International students bring many benefits to their host countries, including multiculturalism, new perspectives, and money. While international students enrich and diversify school cultures, often these students experience tremendous challenges while living and studying in foreign countries.

The aim of this paper is to examine the principal challenges that international students face when studying in Canada and to offer suggestions to postsecondary institutions for improving the services they provide to this learner group. Although all postsecondary students are entitled to excellence in services and supports, given the financial investments of international students in Canadian educational settings, the importance of supporting and enabling them to achieve success goes without saying.

The writer's interest in this topic stems from her work. In addition to working at a private international language academy in Toronto, Ontario, and teaching adults ranging in age from 17 to 50 , she teaches international students at two postsecondary institutions, also in Toronto. Her students come from countries around the world, including but not limited to China, Japan, Korea, Vietnam, Russia, Saudi Arabia, Turkey, Italy, Spain, Mexico, Venezuela, Colombia, and Brazil. These students bring unique experiences, skills, and expectations to the classroom. While the focus of their learning is language development, each student has his or her own personal goals, and upon achieving an adequate level of proficiency in English, the majority aspire to study at a Canadian university. 
The paper begins by introducing two international students who came to Canada to learn English. While the core representations of the students are accurate, certain details have been fictionalized to protect the students' privacy. A review of relevant literature with commentary on its applicability to the two students follows. Suggestions for how educators and institutions may better support international students so they are successful in their postsecondary pursuits are offered. Although appropriate teaching and learning strategies are part of such students' success, so too is knowledge of the issues they face outside of the classroom, including culture shock, the search for identity, and mental health challenges.

\section{The International Student Learning English in Canada}

Those who have taught English as a second language (ESL) have met students struggling with the international experience and with adapting to living and studying in Canada. The reasons for this struggle are diverse. Many students contend with language barriers and have difficulty coping and functioning in an English-speaking environment. Some experience intense homesickness and long to return to family, friends, and the comforts of their home countries. Others may experience difficulties with the practicalities of living in a foreign country and become overwhelmed by banking matters, living arrangements, and issues related to visas and immigration. In the following paragraphs, the adjustment experiences of two international students who came to Canada to learn English are described. These students were selected for consideration because they encountered many of the problems that international students face. Their experiences tell us much about what our universities and other educational institutions need to do better as they open their doors to international students.

\section{Ahmet from Eastern Europe}

Ahmet was a 24-year-old male from Eastern Europe who came to Canada to study English for a year. Ahmet had previously studied engineering, and his plans were to improve his English skills, take the TOEFL (Test of English as a Foreign Language), and enter a Canadian institution to pursue a diploma program related to engineering. After graduation, he intended to return home. He believed that the combination of gaining new language skills and studying in a foreign setting would help him to secure a solid position in an engineering company. When Ahmet was placed in the class, his skills were average for the level. It was clear that if Ahmet wanted to achieve his goal, he would have to work very hard and be patient with the learning process.

Ahmet's nature made him a welcome member of the class. Engaged and funny, he worked well with other students and asked lots of questions. His skills improved quickly because he was dedicated to his studies, completed homework, and grasped new language concepts easily. However, although Ahmet had many friends within the class, he failed to develop a social circle outside of it. Beyond class, he spent much of his time alone and began, quite quickly, 
to miss his family, his girlfriend, and his country. As the term passed, Ahmet's attendance and motivation wavered. Ahmet shared that he felt as though he had nothing of substance in Canada—no family, no friends, no job, no network. While he was in Canada solely to learn English, he quickly lost the desire to do so. He also stressed his strong dislike for Canadian food. Despite many efforts to support him, Ahmet returned to his country before completing his planned year of study.

\section{Juan from South America}

Juan was a male in his mid-30s with a successful career in his home country in South America. Despite his work success, Juan chose to leave his wife and young family and come to Canada. His goal was to study English for a year, get accepted to a particular program, apply for permanent residency, and bring his family to Canada to live with him. Working to escape the difficult situation in his country, he understood that bringing his family to Canada and becoming citizens would be a long and challenging process. As a highly motivated learner, he brought wonderful energy and enthusiasm to the classroom.

Occasionally, though, Juan would become completely distracted by his phone and be disengaged during class. When asked about his behaviour, he would apologetically explain that he was communicating with his wife because his family was in a dangerous situation. He would often worry about his family, and the stress he felt was highly evident. Additionally, he would sometimes miss class because of appointments with the embassy or various government services about visas and immigration papers. After these appointments, he would return stressed or confused by all the paperwork. Unlike Ahmet, Juan is still studying in Canada and working hard to bring his family to the country. However, the challenges that he faces are sometimes overwhelming.

The above profiles of Ahmet and Juan are authentic illustrations of the difficulties that international students in Canada face. Ahmet felt alone, experienced homesickness, and ultimately lost the motivation to study and live in a foreign country. Juan, although committed to his educational and family goals, was anxious about his family's situation and the bureaucratic processes involved in relocating to a new country. Their experiences, although different, are common among international students. The road of the international student learning English in Canada is full of obstacles that native Canadians do not experience when they are planning their educational and life goals. 


\section{Integrating Evidence and Lived Experience}

Although a great deal of research has been done on the student transition experience into postsecondary education in Canada, less research has been done on the transition experience of the international student into Canadian institutions. The numbers emphasize the criticality of this kind of research. According to a Statistics Canada report by Lu and Hou (2015), between 1990 and 1994, Canada admitted 158,000 international students, or about 31,000 students per year. By comparison, between 2010 and 2013, Canada admitted nearly 385,000 international students, or approximately 96,000 per year. Given how dramatic this growth is and the diverse life and learning complexities of this group, it is essential that Canadian institutions do more to understand and support the many international students who study in this country.

The following review of the literature is an effort to contribute to the above goal. In particular, it will examine issues related to culture shock and acculturation; international students' struggle for identity, based on the International Student Identity model; and mental health issues pertaining to international students. In addition to this strictly theoretical review, key themes from the literature will be considered in light of the experiences of the two students described earlier, Ahmet and Juan, who will therefore serve as links between research and lived experience.

\section{Culture and Acculturation}

Adler (1975) proposed the theory of culture shock to explain the transition that individuals experience in new and foreign situations. Although the term culture shock is commonly used to describe people's experiences in foreign countries, the theory can be used to describe any transition, including changing jobs, moving to a different neighbourhood within the same city, or shifting from singlehood to married life (Adler, 1975). Culture shock typically involves five stages: (1) contact, (2) disintegration, (3) reintegration, (4) autonomy, and (5) independence. The first stage, contact, involves excitement and euphoria about the new culture, and individuals are more likely to focus on the similarities that exist between cultures than the differences. During the second stage, disintegration, differences between cultures become increasingly noticeable, and individuals may experience a sense of being different. This leads to the third stage, reintegration, which involves a strong rejection of and hostility toward the second or host culture; at this point, stereotyping and judgmental behaviour may occur. The fourth stage is autonomy, which is characterized by a significant increase in skill with and understanding of the new culture. The individual has a greater grasp of the second culture and is better able to function and cope than earlier. The fifth and final stage is independence, during which individuals understand that they are deeply affected by the second culture and are capable of understanding it at a whole new level. Of course, not all people who undergo transitions pass through all five stages of Adler's (1975) theory. As well, the process may be an iterative one whereby the person moves back and forth between different stages. 
Understanding Adler's (1975) theory of culture shock is important to comprehending the experiences of international students. Their transition into foreign educational institutions is markedly different from the transition of domestic students into the same schools. Not only are international students required to learn where to buy their books, how to pay their tuition, where their classes are, and how to do their homework, but they must also learn to live in a foreign culture and, more often than not, deal with linguistic challenges. Their challenges are clearly quite different from those that domestic students face.

Smith and Khawaja's (2011) study examined the acculturation process, defined as "the dual process of cultural and psychological change that takes place as a result of contact between two or more cultural groups and their individual members" (Berry, 2005, p. 698, as cited in Smith \& Khawaja, p. 701). International students studying in foreign countries experience the acculturation process, which can involve a number of stressors, including language stressors, educational stressors, sociocultural stressors, discrimination, and practical stressors, such as money and accommodation. Failure to properly cope with these stressors can lead to problems with eating and sleeping as well as feelings of loss, anger, and disappointment (p. 706). If students cannot properly navigate the acculturation process or if they fail to acculturate, the impacts can be significant and negative.

\section{Ahmet and Juan}

Thinking about the two students described at the outset of the paper, Ahmet, the student from Eastern Europe, appeared to reach the third stage, reintegration; however, instead of continuing through the rest of the stages, he ultimately rejected Canadian society and returned to his home. By comparison, Juan, the student from South America, progressed into the fourth stage, autonomy, becoming increasingly knowledgeable about Canadian customs and competent at navigating foreign Canadian systems.

Understanding what is involved in the acculturation experiences of international students is important for helping students like Ahmet and Juan succeed. The author's experiences teaching ESL indicate that the stressors students commonly experience are related to language, sociocultural issues, difficulties in making friends, and practical issues such as money and living arrangements. Again, reflecting on the students at the heart of this paper, Ahmet experienced severe sociocultural stressors in that he had difficulty developing a social circle; in addition, he rejected Canadian customs and traditions related to food. Juan, on the other hand, experienced practical stressors such as finding his way through foreign government systems and understanding systems for obtaining visas and immigration papers. Further to this, Juan experienced banking problems, which led to a period of having no money. 


\section{Establishing Identity}

Hotta and Ting-Toomey's (2012) research focused on adjustment patterns related to identity for international students and how friendships contribute to the adjustment process. In their work, they presented three main themes: (1) identity adjustment and communication shifts, (2) cultural and personal time sense in friendships, and (3) identity shock and friendship dialects. The first theme, identity adjustment and communication shifts, involves an awareness on behalf of the student of the need to change his or her expectations, mindset, and communication style in the host country. International students understand that they must communicate and interact with others in ways that are different from their home countries. The other two areas are specifically related to establishing friendships in the host country. The second theme, cultural and personal time sense in friendships, highlights the sentiment of international students that establishing new friends takes time and, further, that friendships formed in the new country lack the depth and closeness of friendships from home countries. The third theme, identity shock and friendship dialects, relates to the emotional challenges that international students experience in trying to establish friendships in the host country. This circumstance can lead to the contrasting feelings that international students sometimes experience in their attempts to make friends. International students report feelings of invisibleness; feelings that their friendships in the host country are relatively closed in nature in comparison to their friendships in their home countries; and feelings of being a guest or even an alien in the host country.

Hotta and Ting-Toomey's (2012) research, showing how international students feel that they need to change their beliefs and communication styles in a foreign country and how they think about developing friendships, is helpful in understanding adjustment patterns. International students generally recognize the need to adapt to a foreign culture and make efforts to do so, regardless of whether or not their efforts are successful. Further, Hotta and TingToomey's findings on friendships are telling for what they reveal about the very emotional aspect of friendships. Generally, international students find that friendships created in host countries lack depth. These perceptions and the consequent emotions impact the students' sense of safety and security in the host country. Finally, the fact that many students report feeling like a guest or alien in a host country is troubling. Although to some extent these feelings are natural and expected, if a student experiences such emotions to a high degree, problems can arise.

\section{Ahmet and Juan}

With respect to Ahmet and Juan, Ahmet failed to establish intimate relationships with his classmates and beyond the school setting. Likely, Ahmet viewed himself as an "alien" in Canadian society. Perhaps these feelings stemmed from the fact that he was unable to use English fluently and consequently was unable to develop friendships easily. As a result of these strong feelings of being different, Ahmet surrendered and decided to return home, where he felt 
comfortable and had many close relationships. Juan, by contrast, recognized the need to adapt his communication style and expectations for Canada. Because his goal was to remain in Canada and bring his family to the country, he was uniquely aware of the need to learn about his host country. Unlike Ahmet, Juan wanted to thrive in Canada and made great efforts to achieve his goal.

\section{Social Identity and Power}

Ullman (1997) defined social identity as follows: "Social identity can be seen as the various ways in which people understand themselves in relation to others, and how they view their past and future" (p. 1). Moving and adapting to life in a new country involves changes in how one views the self and understands relationships with other people. When adults live in a country different from their own, they must renegotiate power relationships. Ullman describes how parents may need to reconsider their relationships with their children in a foreign country, where they may need to depend on their children to help them overcome language barriers. Or, in work and school contexts, a person who is new to the country may be asked or expected to take on a greater or lesser workload than other members of the group, depending on how others perceive the person's abilities and contributions. Depending on the person's comfort level with the language and sense of security in social relationships, he or she may not feel confident about expressing a sense of unfairness or ill treatment.

Ullman's (1997) ideas about social power and changes in identity when living in a foreign country are highly relevant to international students, who experience feelings of aloneness and uncertainty. While they are capable of having meaningful lives in their own cultures, in a foreign culture, they can feel lost and incapable. Embarrassing moments can arise because of a lack of cultural knowledge. Such moments may cause the person to feel resentment toward the host culture and a sense of not belonging.

\section{Ahmet and Juan}

Ahmet is an example of a student who struggled with his change in social identity upon moving to Canada. In his home country, he had many friends, was involved in various aspects of his university community, and had goals and ambitions. However, upon arriving in Canada, Ahmet realized that he had very little in the country and that he needed to begin again at making friends and establishing his place in a new society. This lack of place and power in Canada was extremely difficult for Ahmet; thus, he returned to his country, where he felt he had a real place and degree of power over his circumstances. Juan also struggled with a decreased sense of power and a change in social identity. Because he was far from his family, he lacked the power to care for them that he had when he was living in South America with them. Further, he lacked power related to his limited knowledge of how to deal with Canadian government systems. In his home country, he was able to access and navigate public services, but accessing this information was much more difficult in Canada. 


\section{The International Student}

Kim (2012) developed the International Student Identity (ISI) model and used it to discuss how international students re-examine their identity after moving to a new country. Based on his study, Kim proposed a six-stage model: (1) pre-exposure, (2) exposure, (3) enclosure, (4) emergence, (5) integration, and (6) internalization. In the first stage, pre-exposure, international students prepare for the new country, and their cultural values and family strongly influence their understandings of self and the world. Before leaving their home countries, these students may feel a sense of superiority over their peers for being the "chosen ones" with the opportunity to study abroad (Kim, 2012, p. 108). In the second stage, exposure, international students begin to understand that the home country and the host country are different in a variety of ways, and many develop a strong sense of independence. In the third stage, enclosure, students distance themselves from their surroundings and become increasingly isolated from their peers, with the exception of relationships with a select few who share their situation, often culturally. In stage four, emergence, international students may begin to break boundaries and make efforts to develop a wider range of relationships and to participate in a variety of activities. In stage five, integration, international students make important steps in reconstructing their identities by integrating into their lives new ideas and practices learned from others. Finally, stage six, internalization, is the most mature phase; the international student has a strong system of beliefs and recognizes and respects the diversity of others in the learning environment. Such students regard themselves to be "international citizens in a global society" (Kim, 2012, p. 110). These six phases are fluid and interact with the environment, and the first five must be completed before the final one.

Kim's (2012) ISI model, although presented here as specific to the university student, can be extended to all students who study abroad in foreign educational institutions. The ISI model offers a relatively optimistic outlook on the international student transition experience. While the model acknowledges the difficulties that international students experience, particularly with respect to isolation, it also suggests that most international students resolve their identity crises in positive ways, including acceptance and greater understanding of themselves and other cultures.

\section{Ahmet and Juan}

Ahmet reached the third phase of the ISI model. Feeling isolated from Canadian society and struggling to develop relationships with other members of the class and outside of school, he felt cut off from the wider Canadian community. By comparison, Juan advanced to phases four and five, emergence and integration. He worked to break boundaries and to make Canadian culture his own culture. At the same time, he did not want to leave his South American roots behind. 


\section{Mental Health}

Moores and Popadiuk (2011) have examined the transitions and challenges that international students face, including those related to mental health and thus involving counselling. Further, they have expressed concern that international students are too often treated as a homogeneous group rather than as individuals with separate identities and unique mental health needs. Some international students suffer mental health problems as a result of stressors related to academic performance, social situations, drop-out rates, English skills, and vocational supports. Popadiuk and Arthur (2004) stated that approximately 20\% of the general American population has experienced a psychological disorder in their lifetime; if international students run a similar risk for developing a disorder, which is likely, then this group should not be overlooked. It follows, too, that the risk is higher for international students, given the complexities they encounter that other students do not.

Counsellors also face challenges in working with international students. International students may be unwilling to seek help for a variety of reasons, including stigma about mental health disorders in their own countries, cultural differences about how mental health issues are handled, and a general lack of knowledge about available services. Popadiuk and Arthur (2004) offered suggestions to improve counselling services for international students. These suggestions include better promotion of mental health services; making services more accessible; customizing group interventions, perhaps by organizing sessions for specific cultural groups; and increasing counsellors' multicultural competencies.

The mental health of international students is an extremely important issue for educational institutions. The transition to a foreign country can, as previously discussed, be extremely challenging, and mental health issues, such as depression and anxiety, can arise. Administrators and teachers need to be aware of the common issues that international students experience, and be prepared to take steps to ensure that services such as counselling and support groups are available and accessible. Further, efforts need to be made to break down barriers that may prohibit students from accessing services, including stigma, fear, and embarrassment.

\section{Ahmet and Juan}

Although Ahmet and Juan exhibited sound mental health, they also felt anxiety and stress related to living in a new country. Ahmet experienced social stress because he lacked friends and a social support network. Juan experienced the stress of being far from his family, who were living in a dangerous political situation. He also experienced stress because of various Canadian policies. Ahmet recognized his unhappiness and made changes that affected his original goal to remain in Canada. Juan, by comparison, was quick to ask for help and developed a secure network to support him. It is possible that if these students had not been mentally and emotionally strong, they could have developed mental health issues related to the serious stressors in their lives as international students. 


\section{What Does This Mean for Practice? Insights and Strategies}

There are many ways by which international students can make the transition to a new country and learning setting a more positive one, as well as ways their schools can help them with this progression. In this final section, recommendations are made at three levels: the student, extracurricular and preparatory programs, and the classroom itself. Each area holds significant potential for lessening the stressors of the international student and enabling meaningful cultural and learning experiences.

An international student studying in Canada experiences challenges linguistically, socially, and personally. In particular, he or she lacks an identity in the host culture and requires concrete ways to carve a niche in a foreign society. Possible ways for students to develop identity include becoming involved in activities outside of the classroom, such as volunteering, working at a part-time job, and living in home stays. In addition to learning new vocabulary, the student in each of these situations has the opportunity to interact with a variety of people from the community and to learn about the social and emotional aspects of the culture. More important, a home stay offers a very different relationship from the relationship one typically has with a landlord. Because of the nature of the agreement, home-stay hosts tend to be like family, and the student is likely to feel a strong connection to the other members of the household.

Most educational institutions offer an orientation, specific for international students, which is important and valid. However, in the author's experience, many students have indicated that they desire even more support. The following presents a description of a good program in which the aim is to ensure preparation of the international student on several levels, including life in the community and outside of the classroom.

Given the huge number of international students who study in Toronto, the University of Toronto has recognized the need to support these students and has developed a program called Green Path. Green Path is a 12-week summer course that is designed to prepare Chinese international students to study in Canada. Students take language courses to ensure that their language skills are satisfactory and participate in group activities that take them to various attractions around Toronto so they become familiar with the city and culture before beginning classes. Through the program, students develop relationships with each other, meet some of their professors before classes, learn about Canada, and settle into the city. The advantages of the program are numerous and self-evident (University of Toronto, n. d.). 
Teaching and learning are experiences that some people may take for granted. This is especially problematic when one thinks about learning a language-one of the most life-changing and complex undertakings a person can do. As well, just because a person can speak English does not mean that he or she will make a good teacher of English as a second or third language. While the literature contains many recommendations for improving language learning, three ideas stand out: the preparation of the teacher, the person of the teacher as one who can create a situation of cultural safety, and the use of tried and true as well as emerging pedagogies and technologies for learning.

Foremost, the teacher requires preparation in the principles and practices of andragogy as well as second-language instruction. Teaching international students at the postsecondary level is a complex undertaking. The teacher needs to embrace the learner as a person with a complex life and responsibilities that may extend across oceans, difficult politics at home, and the circumstances of being in a foreign country. Knowles $(1975,1980)$, regarded to be the originator of the term andragogy to designate adult education, refers to adult education as a process experience rather than a content event. Nowhere is there greater truth to this idea of learning as process than in second-language instruction. Adult learners of language tend to be problem oriented and desire information that is realistic and applicable to their lives. Teachers of international students need to bear these ideas in mind.

By character, the teacher needs to be culturally aware and able to facilitate a learning setting where students feel safe. Students need to feel secure and respected so they will take the chances necessary in learning a language, particularly in relation to speaking. While cultural awareness, competence, and safety are discussed extensively in the healthcare literature (Jacklin, 2009), they are equally important among educators teaching and working with international students.

Finally, in addition to using tried and true practices in second-language instruction, teachers should be empowered to try innovative strategies, including those that have recently emerged with new technologies. If students have mobile phones and/or tablets, the teacher may wish to consider how such devices can be used to support interaction and language development (Mang \& Wardley, 2013). Similarly, there is promising research on the use of 3D virtual environments for learning language. All of these strategies should be part of the pedagogical roster of the educator who works with international students.

\section{Final Thoughts}

Certainly, the number of international students studying abroad continues to grow, and this has important consequences for host countries, educational institutions, and those who teach in situations of second language. Educational institutions with a commitment to international students have a vested interest in being aware of the unique challenges and transition 
experiences that international students face, and need to be sensitive to the fact that these students' experiences are as diverse as the countries they come from. International students experience difficulties learning about and adapting to a different culture, challenges in creating and establishing identity in foreign places, and, sometimes, mental health problems associated with stress and anxiety. The profiles of the two students presented in this paper have shown that such challenges are real: They are not simply ideas or stereotypes.

In short, educational institutions need to ensure that services specific to the needs of international students are available and accessible. Likewise, international students need ready access to information and guidance in relation to the steps they should take to integrate successfully into a new culture. Superior teachers with relevant background and experience, appropriate credentials, and an empathetic nature are essential to the success of international students. These components, working together, are critical to the positive life, learning, and language experiences of the increasing numbers of international students in the postsecondary environment in Canada.

\section{References}

Adler, P. (1975). The transitional experience: An alternative view of culture shock. Journal of Humanistic Psychology, 15, 13-23.

Hotta, J., \&Ting-Toomey, S. (May 2012). Intercultural adjustment and friendship dialectics in international students: A qualitative study. Paper presented at the International Communication Association conference, Phoenix, AZ.

Jacklin, K. (2009). Diversity within: Deconstructing Aboriginal health. Social Science and Medicine, 68(5), 980-989.

Kim, E. (2012). An alternative theoretical model: Examining psychological identity development of international students in the United States. College Student Journal, 46(1), 99-113.

Knowles, M. (1975). Self-directed learning: A guide for learners and teachers. New York, NY: Cambridge Book Co.

Knowles, M. (1978). The adult learner: A neglected species. Houston, TX: Gulf Publishing.

Knowles, M. (1980). The modern practice of adult education. New York, NY: Association Press.

Lu, Y., \& Hou, F. (2015). International students who become permanent residents in Canada. Insights on Canadian Society (Statistics Canada). Retrieved from http://www.statcan .gc.ca/pub/75-006-x/2015001/article/14299-eng.htm

Mang, C., \& Wardley, L. (2013). Student perceptions of using tablet technology in post-secondary classes. Journal of Learning and Technology, 39(4), 1-16.

Moores, L., \& Popadiuk, N. (2011). Positive aspects of transitions of international students: A qualitative inquiry. Journal of College Student Development, 52(3), 291-306. 
Popadiuk, N., \& Arthur, N. (2004). Counseling international students in Canadian schools. International Journal for the Advancement of Counselling, 26(2), 125-145.

Smith, R. A., \& Khawaja, N. G. (2011). A review of the acculturation experiences of international students. International Journal of Intercultural Relations, 35, 699-713.

Ullman, C. (1997). Social identity and the adult ESL classroom. ERIC Digest. Washington, DC: National Clearinghouse for ESL Literacy Education. Retrieved from http://eric.ed.gov/?id=ED413795

University of Toronto. (n.d.). Green Path Program - China. Retrieved from http://utsc.utoronto.ca/greenpath-china/welcome-green-path

\section{Corresponding Author}

Alanna Carter

alanna.carter@senecacollege.ca

\section{Biography}

Alanna Carter has taught international students at the University of Toronto, at Seneca College (Toronto), and in the private education sector. Alanna's expertise in English as a second language builds on her undergraduate degrees in English (Dalhousie University) and education (University of Ottawa). She also holds an MEd from the University of New Brunswick, in which she concentrated on curriculum development for language acquisition and the experiences of international students in Canada.

Alanna Carter a enseigné à des étudiants internationaux à l'Université de Toronto, au collège Seneca (Toronto) et dans des établissements d'enseignement privé. Son expertise dans l'enseignement de l'anglais langue seconde s'est bâtie sur ses diplômes de premier cycle en études anglaises (Université Dalhousie) et en éducation (Université d'Ottawa). Elle détient également une maîtrise en éducation de l'Université du Nouveau-Brunswick, où ses travaux ont surtout porté sur la création d'un programme visant l'acquisition du langage et sur les expériences des étudiants étrangers au Canada. 